\title{
Audit of general surgical pathology experience of histopathology trainees
}

\author{
G J Tildsley, S A Dilly
}

\begin{abstract}
Surgical histopathology is learnt principally by the practical experience of reporting routine cases. This study performed a quantitative audit of the types of specimens reported by trainees at a teaching hospital and a district general hospital. At the teaching hospital all cases are seen by trainees and it was predicted that the distribution of specimens among trainees would be entirely random. Significant variations were found in the number of skin, breast, cervix, prostate, and endometrial cases reported by each trainee. In some cases this related to a trainee having a special interest (skin and breast pathology) or areas requiring special techniques (breast pathology). At the district general hospital the workload was much higher so that juniors did not see all cases and junior trainees were not seeing bronchial, liver, or lymph node biopsy specimens.
\end{abstract}

This type of audit shows that in teaching hospitals specialisation by some trainees (as encouraged by the new MRCPath exam) may be to the detriment of others and that in district general hospitals pressure of work may actually reduce a trainee's exposure to difficult cases. Without systematic audit this would not be recognised and remedied.

Histopathology is learnt principally from practical experience augmented by postgraduate courses; therefore it is important that all trainees should have exposure to a broad range of specimens. Generally it is felt that if trainees participate on rotas through a variety of laboratories then they will gain a balanced histopathological education. This balance may be upset if specimens of special interest bypass trainees to go directly to a specialist consultant or if senior registrars develop increased expertise in certain fields, as the new MRCPath examination proposes, ${ }^{1}$ which may be at the expense of other trainees.

The surgical experience of a trainee pathologist cannot be gauged by dividing the total number of specimens seen at a hospital by the number of trainees. This ignores both the effect of special interest (or disinterest) in a subject and specimens bypassing trainees because of urgency or a heavy workload. Objective assessment of surgical experience is not difficult if a department is computerised and has the appropriate software.

Audit of pathology is increasing but generally concentrates on the quality of tests and reports, the turnaround time of specimens, and the laboratory workload. Areas subject to audit are likely to receive greater attention than non-audited aspects (such as training) of a histopathology department. The present study audits the surgical pathology experience of trainees in the South West Thames region training scheme and provides a method which could be used by other hospitals.

A regular systematic audit of the surgical pathological workload of trainees would allow deficient areas to be identified so that appropriate additional experience could be gained. In the longer term it would be a way of monitoring any effects of the White Paper or changes in the MRCPath examination system.

\section{Methods}

Two hospitals were studied-a teaching hospital (St George's Hospital, London) and a district general hospital with two trainees (Kingston Hospital, Surrey.)

\section{ST GEORGE'S HOSPITAL}

A six month period from October 11989 to March 311990 was studied and all specimens coded as breast, skin, liver, appendix, prostate, colon or rectum, lung or bronchus, endometrium, bladder, cervix, and products of conception were included. The areas were chosen to provide a basis for training as a general histopathologist and totalled 2976 out of the 4883 cases coded on the computer during the period.

The data were collected from our departmental computer using the ADHOC search facility on CILMS software supplied by ACT Medisys. The search variables used were the coding for the pathologist combined with the SNOMED coding for each site. The numbers of cases seen from each area by each pathologist are expressed as a percentage of the total number of cases seen by that doctor to avoid complicating factors such as staff turnover and leave.

Statistical analysis was made using the standard error of difference between percentages, and a level of significance of $p<0.05(1.96$ standard errors) was chosen.

The cases of breast pathology were further subdivided by procedure ( $x$-ray localisation, frozen section) and diagnosis (table 1). The 
Table 1 Diagnostic categories of breast pathology

\begin{tabular}{lll}
\hline Benign simple diagnoses & Benign complex lesions & Malignant lesions \\
\hline Normal & Sclerosing adenosis & $\begin{array}{l}\text { Includes invasive and in situ } \\
\text { carcinomas }\end{array}$ \\
Fibrosis & Blunt duct adenosis & \\
Fibroadenoma & Radial scar & \\
Inflammation/foreign body & Papillomata & \\
Involution & Atypical lobular hyperplasia & \\
Lactation & & \\
Hypertrophy & & \\
Gynaecomastia & & \\
Epitheliosis & & \\
\hline
\end{tabular}

frozen sections performed were analysed as a proportion of breast cases seen by each junior.

KINGSTON DISTRICT GENERAL HOSPITAL

A three month period from January 11990 to March 311990 was studied. Reports were sorted manually into the specimen types (the identity of the pathologist reporting does not go on to computer) and subjected to the same statistical analysis as that performed on the $\mathrm{St}$ George's material.

\section{Results}

In both hospitals pre-MRCPath senior registrars show all requests to consultants who may allow specified cases to be checked out alone. Post-MRCPath senior registrars report cases alone at their own discretion, within informal guidelines from the individual consultant.

\section{ST GEORGE'S HOSPITAL}

Two thousand nine hundred and seventy six cases out of 4883 coded in the department during this time were studied. Registrars on the normal rota saw an average of 83 of these specimens a calendar month and established senior registrars (whose rota differs) an average of 56 a calendar month.

The cases, expressed as a percentage of the material seen by that person, are listed in table 2 . The result of the subdivisions of breast cases are listed in table 3. SR5 saw a highly significantly increased number of skin cases $(p<0.01)$, while SR1, SR3, SR6, R2 and R4 saw a reduced number of skin cases. SR7 also saw a significantly increased ( $p<0.05$ ) number of skin cases.

SR4 and SR6 saw a significantly increased number of cervical cases, and SR1 saw a significantly increased number of endometria. SR2 saw a reduced number of endometria and SR6 saw a reduced number of prostates.

Three SRs (SR2, SR4, and SR6) saw a significantly increased number of breast cases. SR1 and R2 saw a reduced proportion of frozen sections and SR4 saw an increased proportion of cases with frozen sections (table 3 ). Eleven of $14 x$-ray localisation specimens were dealt with by three SRs, SR2, SR6, and SR7. Diagnostic categories did not seem to vary widely among the different trainees.

Within the diagnosis codes the area of interest chosen for review was "complex benign" lesions. Four of 17 cases were reported by SR2 (who also reported significantly more breast cases than the average, and was one of those performing the bulk of the $x$-ray localisation specimens.) Three of 14 of the cases on which $x$-ray localisation was performed and seven of 116 frozen section cases gave complex benign diagnoses. Thus it seems likely that the number of complex cases seen reflects only the total number of breast specimens seen.

KINGSTON DISTRICT GENERAL HOSPITAL

One thousand two hundred and thirty two of the 2272 cases received in the department in the period studied were tabulated (table 4 ). The registrar saw an average of 82 of these cases a month, the senior registrar 105 , and the consultants signed out alone an average of 223 .

The registrar saw a reduced number of lung and bronchus, liver, and lymph node cases, and an increased number of appendix, prostate, and cervical cases.

The senior registrar saw an increased number of skin, prostate, and lymph node cases, and a decreased number of endometria, cervices, and products of conception. The consultants reported alone a decreased number of skin and prostate cases and an increased number of endometrial and bladder cases.

\section{OTHER HOSPITALS}

Four other hospitals participate in the training of pathologists. At St Helier's Hospital (one senior registrar and one registrar) a total number of 13500 surgicals a year is seen. The department is computerised (ITL Multilab). The name of the junior seeing a case is not recorded and so audit of training is not possible.

Table 2 Cases seen by each pathologist, expressed as a percentage of their surgical work, together with the numerical totals of cases seen

\begin{tabular}{|c|c|c|c|c|c|c|c|c|c|c|c|c|c|}
\hline & Breast & Skin & $\begin{array}{l}\text { Colon } \\
\text { rectum }\end{array}$ & $\begin{array}{l}\text { Lung } \\
\text { bronchus }\end{array}$ & Liver & Appendix & Prostate & Endometrium & Bladder & Cervix & POCS & $\begin{array}{l}\text { Lymph } \\
\text { nodes }\end{array}$ & Numerical \\
\hline $\begin{array}{l}\text { SR1 } \\
\text { SR2 } \\
\text { SR3 } \\
\text { SR4 } \\
\text { SR5 } \\
\text { SR6 } \\
\text { SR7 } \\
\text { R1 } \\
\text { R2 } \\
\text { R3 } \\
\text { R4 } \\
\text { Total }\end{array}$ & $\begin{array}{r}4.08 \\
10.73 \\
6.19 \\
10.64 \\
6.87 \\
13.39 \\
5.76 \\
7.11 \\
6.95 \\
4.02 \\
4.47 \\
6.55\end{array}$ & $\begin{array}{l}\frac{29 \cdot 08}{36 \cdot 16} \\
32 \cdot 47 \\
\frac{26 \cdot 60}{47 \cdot 85} \\
\frac{26 \cdot 79}{42 \cdot 80} \\
\frac{33 \cdot 89}{36 \cdot 89} \\
\frac{26 \cdot 33}{34 \cdot 69}\end{array}$ & $\begin{array}{r}13.78 \\
14.69 \\
14.95 \\
11.70 \\
9.87 \\
13.39 \\
9.47 \\
12.09 \\
13.90 \\
12.05 \\
9.96 \\
11.86\end{array}$ & $\begin{array}{l}5 \cdot 06 \\
0 \cdot 56 \\
2 \cdot 06 \\
4 \cdot 26 \\
2 \cdot 58 \\
2 \cdot 68 \\
3 \cdot 70 \\
3 \cdot 32 \\
7 \cdot 25 \\
5 \cdot 22 \\
5 \cdot 69 \\
4 \cdot 13\end{array}$ & $\begin{array}{l}1.02 \\
2.82 \\
2.06 \\
2 \cdot 13 \\
0.86 \\
0.89 \\
4 \cdot 12 \\
2.37 \\
1.81 \\
1.61 \\
1.83 \\
1.92\end{array}$ & $\begin{array}{l}4 \cdot 59 \\
6 \cdot 21 \\
4 \cdot 12 \\
2 \cdot 13 \\
3 \cdot 22 \\
5 \cdot 36 \\
3 \cdot 70 \\
5 \cdot 69 \\
5 \cdot 74 \\
2 \cdot 41 \\
5 \cdot 69 \\
4 \cdot 60\end{array}$ & $\begin{array}{l}1.53 \\
3.39 \\
5.67 \\
3.19 \\
4.08 \\
0.89 \\
5.76 \\
6.40 \\
5.44 \\
6.83 \\
4.67 \\
4.77\end{array}$ & $\begin{array}{c}\frac{18.88}{11.30} \\
\frac{17.01}{18.09} \\
14.81 \\
12.50 \\
15.64 \\
11.61 \\
14.80 \\
14.46 \\
16.87 \\
14.95\end{array}$ & $\begin{array}{l}3.57 \\
1.69 \\
4 \cdot 12 \\
2 \cdot 13 \\
2.36 \\
5.36 \\
2.47 \\
3.55 \\
5 \cdot 14 \\
4.82 \\
3.86 \\
3.56\end{array}$ & $\begin{array}{r}8.67 \\
7.34 \\
8 \cdot 25 \\
12.77 \\
4.08 \\
16.96 \\
4 \cdot 12 \\
6.64 \\
4.83 \\
6.83 \\
8.94 \\
7.09\end{array}$ & $\begin{array}{l}6.63 \\
3.95 \\
2.58 \\
3.19 \\
2.15 \\
0.89 \\
2.06 \\
5.21 \\
5.74 \\
6.43 \\
5.28 \\
4.27\end{array}$ & $\begin{array}{l}2.55 \\
1.13 \\
0.52 \\
3.19 \\
1.29 \\
0.89 \\
0.41 \\
2.13 \\
1.51 \\
2.01 \\
2.24 \\
1.65\end{array}$ & $\begin{array}{r}196 \\
177 \\
194 \\
94 \\
466 \\
112 \\
243 \\
422 \\
331 \\
249 \\
492 \\
2976\end{array}$ \\
\hline
\end{tabular}

All figures underlined are significantly different from the mean $(p<0.05)$. 
Table 3 Subdivision of breat cases expressed in absolute numbers

\begin{tabular}{lcccccc}
\hline & $x$-ray & $F / S$ & $\begin{array}{l}\text { Benign } \\
\text { simple }\end{array}$ & Complex & Malignant & Total \\
\hline SR1 & - & 3 & - & - & 8 & 8 \\
SR2 & 5 & 10 & 8 & 4 & 7 & 19 \\
SR3 & - & 6 & 8 & 1 & 3 & 12 \\
SR4 & - & 9 & 7 & 1 & 2 & 10 \\
SR5 & 1 & 22 & 22 & - & 10 & 32 \\
SR6 & 3 & 10 & 9 & 2 & 4 & 15 \\
SR7 & 3 & 7 & 10 & 1 & 3 & 14 \\
R1 & - & 18 & 19 & 4 & 7 & 30 \\
R2 & - & 10 & 14 & - & 9 & 23 \\
R3 & 1 & 6 & 6 & - & 4 & 10 \\
R4 & 1 & 15 & 7 & 3 & 12 & 22 \\
\hline
\end{tabular}

Figures underlined deviate significantly from the average mean (as a percentage of the cases seen by that pathologist); underlined figures are significantly lower than the mean.

At the Royal Surrey County Hospital (one registrar) the number of surgical specimens seen annually is 9500 and the department is being computerised (Cellnet system). At the Mayday (one registrar) 11600 surgical specimens a year are seen. The department uses a "Pathway" computer system developed by the South West Thames regional computer centre, which could be used for this kind of work. At the Royal Marsden Hospital (a specialist cancer hospital with one senior registrar and one registrar) 3500 surgical specimens a year are seen. The Hewlett-Packard computer runs an in-house system, which at present does not code the junior pathologists.

\section{Discussion}

The number of cases seen by an individual doctor is a quantifiable measure of his or her experience. Although their education consists of many components, it is important to ensure a wide exposure to routine general surgical work. This audit has shown certain discrepancies, the causes and consequences of which it is useful to consider.

ST GEORGE'S HOSPITAL

A major area of variation is in the dermatopathology cases seen. SR5 has a particular interest in, and knowledge of, dermatopathology and would be expected to be involved in the final report of many cases. Her enthusiasm, however, has resulted in a reduction in the number of these cases that other juniors report,

Table 4 Cases seen at Kingston hospital, expressed as a percentage of surgical work, together with numerical totals of cases seen

\begin{tabular}{|c|c|c|c|c|}
\hline $\begin{array}{l}\text { Case type } \\
\text { (as percentage) }\end{array}$ & $R$ & $S R$ & $\begin{array}{l}\text { Consultant } \\
\text { (alone) }\end{array}$ & Mean \\
\hline $\begin{array}{l}\text { Breast } \\
\text { Skin } \\
\text { Colon and rectum } \\
\text { Lung and bronchi } \\
\text { Liver } \\
\text { Appendix } \\
\text { Prostate } \\
\text { Endometrium } \\
\text { Bladder } \\
\text { Cervix } \\
\text { POCS } \\
\text { Lymph nodes } \\
\text { Numerical total }\end{array}$ & $\begin{array}{r}3 \cdot 7 \\
42 \cdot 7 \\
6 \cdot 5 \\
0.8 \\
0 \\
\frac{7 \cdot 3}{10 \cdot 6} \\
10 \cdot 2 \\
1.6 \\
11 \cdot 0 \\
5 \cdot 7 \\
0 \\
246\end{array}$ & $\begin{array}{r}4 \cdot 1 \\
51 \cdot 6 \\
6 \cdot 6 \\
1 \cdot 6 \\
0.6 \\
5 \cdot 7 \\
\frac{13 \cdot 0}{7 \cdot 6} \\
\frac{7 \cdot 3}{1 \cdot 3} \\
\frac{3 \cdot 8}{2 \cdot 2} \\
\frac{1.9}{316}\end{array}$ & $\begin{array}{r}4 \cdot 8 \\
41 \cdot 0 \\
7 \cdot 3 \\
1 \cdot 8 \\
1 \cdot 3 \\
2 \cdot 8 \\
\frac{6 \cdot 1}{14 \cdot 0} \\
\frac{2 \cdot 4}{10 \cdot 4} \\
6 \cdot 3 \\
1 \cdot 3 \\
670\end{array}$ & $\begin{array}{r}4 \cdot 4 \\
44 \cdot 1 \\
7 \cdot 0 \\
1 \cdot 5 \\
0 \cdot 9 \\
4 \cdot 5 \\
8 \cdot 8 \\
11 \cdot 6 \\
1.9 \\
9 \cdot 0 \\
5 \cdot 1 \\
1 \cdot 2 \\
1232\end{array}$ \\
\hline
\end{tabular}

Underlined figures are significantly different from the mean $(p<0.05)$.

R: registrar.

SR: senior registrar. so reducing their exposure to "hot seat" dermatopathology, although they are still able to see the material at meetings. This issue is important to consider because the proposed new examination system for the MRCPath involves encouraging senior registrars to develop special interest areas.

In the case of cervical specimens (SR4 and SR6) and endometrial specimens (SR1) some pathologists have seen a significantly increased number $(p<0.01)$. It is not clear why this has occurred. All junior pathologists were surveyed as to whether they felt they had an "average interest", "below average interest", or "above average interest" in each tissue. Neither SR1, SR4, nor SR6 admitted "above average interest" in gynaecological pathology.

Significantly fewer cases of endometria (SR2) and prostates (SR6) were seen by some SRs, both of whom admit to having below average interest in the respective organ.

Breast cases SR2, SR4, and SR6 saw a significantly greater number of breast cases than the mean, but no juniors saw a significantly reduced number of cases.

Out of 14 cases which underwent $x$-ray localisation, 11 were performed by one of three senior registrars. The time and expertise involved in these cases is considerable and it has been concentrated in these individual doctors for practical reasons.

Due to local surgeons' preferences our frozen section rate on breast specimens is high $(59.9 \%)$, providing wide experience in these cases for trainees. Two doctors, SR1 and R2, performed significantly fewer frozen sections than other junior staff. This imbalance could be prevented by having a rota for frozen section sessions.

KINGSTON DISTRICT GENERAL HOSPITAL

The major difference between a district general hospital and a teaching hospital is not the range of material received but the workload compared with the number of trainees. This means that trainees may not be able to see all the cases and the consultant will report a selection alone. There seems to be tendency for the trainees to see increased numbers of specimens from cases which they are likely to be able to report themselves, such as appendix for the registrar, skin and prostrate for the post-MRCPath senior registrar.

The registrar saw a reduced number of cases of lung and bronchus, liver, and lymph nodes. All these cases are time consuming but they may require prompt issue of a report. A junior's participation may slow the issue of the report. In some cases the junior may see the case, but not be involved in signing out the report, and hence, in this study, be assigned to the "consultant only" group.

The consultants were reporting alone an increased number of endometrial and bladder cases. This may be an attempt to reduce the trainees' amount of potentially more repetitive work such as endometria. 
Kingston Hospital was chosen to study because St Helier Hospital does not record the junior reporting the cases; the Mayday Hospital and the Royal Surrey County Hospital have only one trainee; and the Royal Marsden Hospital is not a district general hospital.

For maximum benefit, this type of study needs to be performed annually and to include all hospitals involved in the training scheme so that a profile of each trainee's experience is available to the relevant consultants. Such work would be relatively simple provided that the departments are computerised and appropriate software included. As departments are called on to produce an increasing range of statistics for financial, managerial, and audit purposes, let's hope that training is not forgotten.

Thanks are given to Dr G Philip for his kind help at Kingston Hospital and comments on the work. The help of other consultants in the region who read and commented on a draft of consultants in the region who read
this study is also acknowledged.

1 Association of Clinical Pathologists. Model training programmes. London: ACP, 1990:4-5. 